\title{
Dense calculi formation resulting in impaction of pancreatic stent
}

\author{
Kurumboor Prakash • N. P. Kamalesh • K. Pramil • Sylesh Aikot • \\ Zacharias Prakash • G. N. Ramesh • Mathew Philip
}

Published online: 4 December 2012

(C) Indian Society of Gastroenterology 2012

\begin{abstract}
A 35-year-old male had pancreatic duct stenting using a $7 \mathrm{~F}$ single-pigtail $10-\mathrm{cm}$ stent 11 years back for chronic pancreatitis. He was lost to follow up and presented recently with recurrent pain of 3 months duration. A computed tomography scan revealed a retained stent with dense calcification extending to side branches with the stent embedded within the calculi, filling the entire length of the pancreatic duct (Fig. 1a). Attempts to retrieve the stent endoscopically using rat tooth forceps, biliary balloon, a Soehendra dilator, and a stent passed parallel to the stent to fragment the calculi failed due to dense impaction and friability of the stent. He underwent surgery. At
\end{abstract}

operation, there were dense calculi in the pancreatic duct and side branches, and inseparable dense calcifications around the retained stent (Fig. 1b). The stent was completely occluded. The stent and calculi were removed, and he underwent lateral pancreatojejunostomy. Pancreatic duct stents, placed for various indications, are known to produce duct and parenchymal changes in $36 \%$ to $50 \%$ of cases [1]. Calcific intrapancreatic embedding of a pancreatic stent requiring surgical removal 10 years after initial deployment is reported [2]. To our knowledge, retrieval of a stent 11 years after the initial deployment has never been reported.
Fig. 1 a and b A CT scan picture and operative photograph showing the retained pancreatic stent with dense adherent calculi filling the main pancreatic duct and extending to its side branches
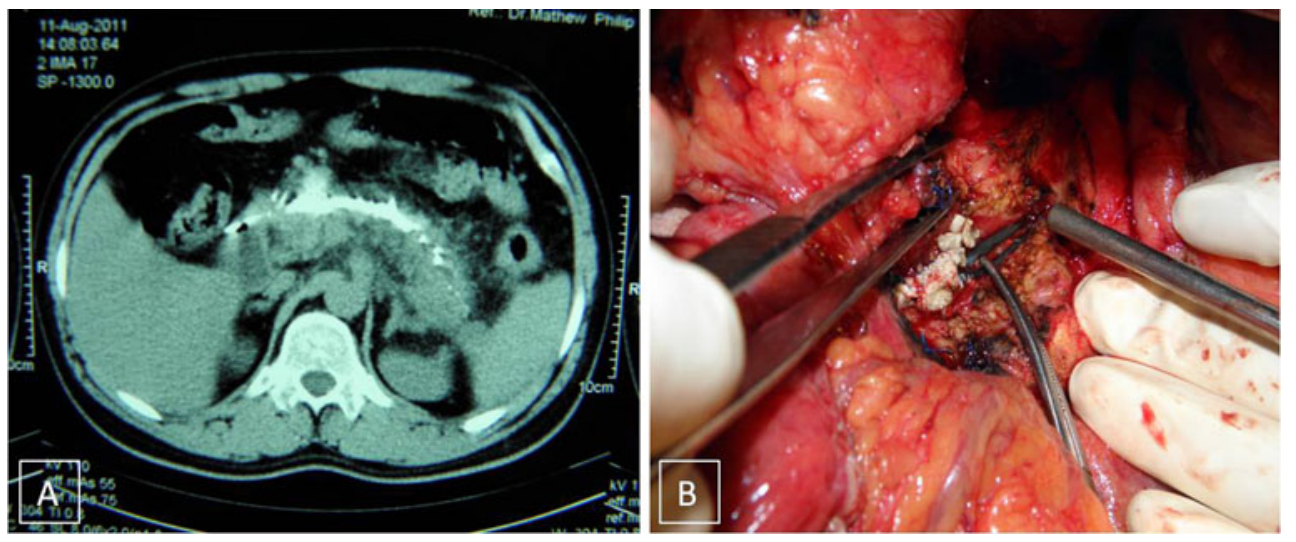

\section{References}

K. Prakash $(\bowtie) \cdot$ N. P. Kamalesh $\cdot$ K. Pramil $\cdot$ S. Aikot

Z. Prakash $\cdot$ G. N. Ramesh $\cdot$ M. Philip

Department of Gastrointestinal Surgery, Digestive Disease Center,

P V S Memorial Hospital, Kaloor,

Kochi 682012 Kerala, India

e-mail: drkprakash@vsnl.com
1. Kozarek RA. Pancreatic stents can induce ductal changes consistent with chronic pancreatitis. Gastrointest Endosc. 1990;36:93-5.

2. Shapiro AM, Scudamore CH, July LV, et al. Calcific intra-pancreatic embedding of a pancreatic stent necessitating surgical removal-a danger of chronic endoscopic retrograde pancreatic stent placement. Gastrointest Endosc. 1999;50:860-2. 